\title{
Using unsorted sweep net samples to rapidly assess macroinvertebrate biodiversity
}

\author{
Melissa Carew ${ }^{1}$, Rhys Coleman ${ }^{2}$, Katie Robinson ${ }^{1}$, and Ary Hoffmann ${ }^{1}$ \\ ${ }^{1}$ The University of Melbourne \\ ${ }^{2}$ University of Melbourne
}

October 15, 2020

\begin{abstract}
Macroinvertebrate biodiversity is routinely used to assess the ecological condition of freshwater environments. Macroinvertebrates are traditionally identified morphologically to mostly family level but using DNA metabarcoding they can be rapidly and reliably identified to species. Developing standardised, robust and cost-effective protocols would enable DNA metabarcoding to be broadly used for routine freshwater biological assessments leading to both potential cost savings as well as increased taxonomic resolution. To further reduce the cost and time it takes to process samples, we examine the feasibility of DNA metabarcoding unsorted macroinvertebrates (macroinvertebrates and debris) from sweep net samples collected from stream pool or edge habitats. We processed these unsorted samples with a standardised method and tested multiple primer sets widely used for invertebrate DNA metabarcoding. We found that currently available DNA metabarcoding primers are well suited for processing unsorted samples, though some performed better than others. However, macroinvertebrate density affected the number of species detected with DNA metabarcoding, particularly the detection of rare taxa. These findings show that DNA metabarcoding of unsorted net contents could streamline macroinvertebrate sample processing for bioassessment, but the optimal amounts of unsorted material for sub-sampling needs to be considered when assessing macroinvertebrate biodiversity.
\end{abstract}

\section{Hosted file}

Bulk sample paper_9_0ct_20_2.pdf available at https://authorea.com/users/367412/articles/ 486850-using-unsorted-sweep-net-samples-to-rapidly-assess-macroinvertebrate-biodiversity 